\title{
Do workers negative self-select when they commute? Evidence for the Chilean case of long-distance commuting
}

\author{
Viviana Carriel $^{1,2}\left(\mathbb{0} \cdot\right.$ Marcelo Lufin $^{2}\left(\mathbb{C} \cdot\right.$ Manuel Pérez-Trujillo $^{2} \odot$
}

Received: 12 April 2021 / Accepted: 7 February 2022 / Published online: 3 March 2022

(c) The Author(s), under exclusive licence to Springer-Verlag GmbH Germany, part of Springer Nature 2022

\begin{abstract}
Long-distance commuting (LDC) as a strategy of labor factor mobility has become relevant in recent decades, mainly in those economies characterized by a significant relative weight of extractive activities. The phenomenon is key to understanding the current structure and dynamics of these labor markets, although little is known about self-selection in LDC. This document addresses this knowledge gap by analyzing the case of Chile using functional areas. Chile is a country where LDC has become the principal strategy of labor mobility and is closely linked to the mining and construction sectors. The results obtained show a pattern of negative selfselection, meaning that it is the least qualified who have the highest probability of commuting between functional areas. Commuting could therefore be more than just a mechanism for accessing qualified labor, allowing less qualified individuals access job opportunities when the labor market where they come from is more qualified.
\end{abstract}

\section{Introduction}

Long-distance commuting (LDC) ${ }^{1}$ is a phenomenon that has gained relevance as a form of labor mobility in countries where extractive activities such as mining or hydrocarbon exploitation are central to overall production (Gramling et al. 1995;

\footnotetext{
${ }^{1}$ LDC considers those workers that are provided food and housing and are therefore able to remain in their place of work for some period of time (Storey and Shrimpton, 1986), instead of returning to their place of residence on a daily basis.

Viviana Carriel

viviana.carrielb@ucuenca.edu.ec

Marcelo Lufin

mlufin@ucn.cl

Manuel Pérez-Trujillo

manuel.perez@ucn.cl

1 GIER - Facultad de Ciencias Económicas y Administrativas, Universidad de Cuenca, Cuenca, Ecuador

2 Departamento de Economía, Instituto de Economía Aplicada Regional (IDEAR), Universidad Católica del Norte, Casa Central. Angamos \#0610, Antofagasta, Chile
} 
Storey and Shrimpton 1988; Houghton 1993). Improvements in transportation and communication infrastructure have allowed more workers to use LDC (Coombes and Casado-Díaz, 2005), paving the way for this strategy of labor mobility to be implemented in economic activities other than extractive industries. ${ }^{2}$ LDC has therefore become a fundamental element in understanding the dynamics and equilibrium of these labor markets.

The objective of this research is to analyze the possibility of negative self-selection in long-distance commuters since the characteristics of commuters are not random. However, a great part of studies in this field indicate that long-distance commuters tend to have a high level of education and therefore receive a wage premium compared to non-commuters (Sandow 2011; Paredes et al. 2017). In addition, the tendency for highly qualified individuals to spatially concentrate in places with a high provision of amenities would make it possible to obtain a wage premium in places with a shortage of qualified labor (Paredes et al. 2017). Self-selection has been developed more extensively within the context of migration. Building off of Roy (1951), works provide evidence for negative self-selection in migration, particularly when the returns to skill differ between the country of destination and the country of residence (Borjas 1987; 1991). We should note that conditions that lead to negative self-selection in migration could also be present in commuting.

The importance of studying this phenomenon lies in the implications that it has on regional development. Melzer and Hins (2019) indicate that the presence of positive self-selection patterns, if maintained over time, can lead to polarized development paths, meaning regions with highly qualified human capital would be negatively affected. The emergence of a pandemic such as COVID-19 limits population mobility (Fang et al. 2020; Klein et al. 2020) and could reveal the dependence on LDC that some regions have as a mechanism for obtaining qualified labor, given that several authors indicate that LDC allows regions to access it (Storey 2001, 2010; Eilmsteiner-Saxinger 2011; Becker and Soosay 2013). On the other hand, negative self-selection could generate imbalances in the local labor market when host regions suffer economic shocks, increasing unemployment among low-skilled workers in LDC regions of origin, especially in those areas with a poor economic performance (Green and Owen 2006).

Self-selection in commuting is less developed than for migration, having primarily been studied using administrative areas, which, as Magrini (2004) indicates, are the result of historical or political processes that are not related to socio-economic factors, and which may conceal regional dynamics such as the dependence on income between areas (Niebuhr 2001) and processes of economic convergence (Magrini 2004). Additionally, in the Chilean context where this research is carried out, several authors have shown that functional areas are more appropriate to analyze labor markets than administrative regions, as they better economic and social dynamics considering the space where they are developed. Therefore, we use functional areas to analyze self-selection in commuting (Berdegué et al. 2015, 2019;

\footnotetext{
${ }^{2}$ In the USA, between 2006 and 2010 about $41 \%$ of commuters belonged to the administration sector and $25 \%$ were employed in the business sector; $9 \%$ belonged to the primary and construction sectors (Rapino and Fields, 2013).
} 
Casado-Díaz et al. 2017; Rowe et al. 2017), and a commuter is defined as someone who moves from their area of residence to another different, functional area of work (Pérez et al. 2020).

The variables schooling and wages are used to approximate the qualification of workers. Following the developments proposed by Chiquiar and Hanson (2005), which are based on the work of Borjas (1991) and Roy (1951), we introduce some new features into the analysis of self-selection process by comparing the distributions for both variables, schooling and wages, between residents and commuters. We also carry out the analysis separately for residential and commuting zones. The results for schooling indicate the existence of negative self-selection. The results when using wages indicate intermediate self-selection. The difference between the self-selection patterns could be explained because the salary would include other unobservable factors in addition to the skill level of commuters.

The rest of the document is divided as follows: Sect. 2 contains the literature review, Sect. 3 contextualizes LDC in Chile, Sect. 4 presents the theoretical framework, Sect. 5 covers the empirical methodology and the data used, Sect. 6 presents the results, and Sect. 7 concludes.

\section{Literature review}

The relevance of LDC at a global level can be illustrated by the fact that it has become a substitute for migratory flows in a large number of economies such as Chile and Australia (Storey 2001, OECD 2005, see Chapter 2). This expansion of the phenomenon makes its study relevant in understanding the current (and future) structure and dynamics of a labor market. Among the factors that favor this form of labor mobility are: (1) the reduction in costs for companies, i.e., having to develop infrastructure for worker accommodations since commuters are housed in sites near extraction areas (Rolfe 2013; Manky 2017), (2) commuters can obtain a higher wage and better job opportunities (So et al. 2001; van Ommeren and van der Straaten 2008; Paredes et al. 2017), and (3) it improves a company's access to skilled labor (Storey 2001, 2010; Eilmsteiner-Saxinger 2011; Markey et al. 2011; Becker and Soosay 2013).

O'Faircheallaigh (1995) mentions that because extractive industries are capitaland technology-intensive, they require specialized labor. In the case of Australia, Storey (2001) indicates that finding skilled and experienced labor in the country's western regions is increasingly complex, which has furthered the use of LDC by companies. In 2010, as part of the development of a sustainability strategy for Australian communities there, nearly $50 \%$ of miners practiced LDC, and companies highlighted it as one of the reasons they were able to quickly attract qualified work (DSEWPAC 2011, p. 40). However, Becker and Soosay (2013) argue that in some cases that LDC has not been sufficient in meeting the demand for skilled labor. This is because the lack of amenities in the regions where extractive activity is carried out does not compensate for the perceived wages.

Several studies have linked a higher educational level with a worker's willingness to commute further distances (Gerstel and Gross 1984; Hogarth and Daniel 1988; 
Green et al. 1999; van Ham 2001; Paredes et al. 2017). This could be explained by the fact that a greater distance implies a higher opportunity cost for individuals with low levels of education (Ong and Blumenberg 1998; Öhman and Lindgren 2003). Highly qualified individuals face an opportunity cost for their education; therefore, they seek a job with an income that compensates for this cost, including in labor markets other than where they come from.

Among the studies that further address the possible self-selection of workers in commuting is that of Sorek (2009), who develops a theoretical model to analyze the effect of a reduction in commuting time on the urbanization process of cities where migration and commuting are expensive. The wage for the least qualified worker is similar between regions, and the only difference between individuals in each city is their productive capacity. The results indicate that the most qualified individuals migrate to the metropolis, those of intermediate ability commute between cities, and the rest work and reside in the suburbs. However, a limitation in the analysis is assuming that individuals with different skill levels face the same costs of commuting and migrating, which might obscure other types of results.

Huber (2014) extends Sorek's analysis by allowing differences in wages between cities for the least qualified, which could encourage them to commute, and also considers age as a factor of selection when commuting. Their results indicate the existence of positive self-selection of commuters when using schooling as a proxy for qualification. Additionally, the positive self-selection of commuters is more marked when they commute to capitals, which Huber (2014) indicates is consistent under the assumption that returns to education are higher in this type of city. On the other hand, when considering the distances traveled, Huber (2014) finds that people with more education are more likely to commute less than $50 \mathrm{~km}$. This paper, however, will assume that individuals with different levels of education have equal commuting costs.

Wrede (2013) shows that individuals with low levels of qualification do not commute long distances, but those with intermediate levels do, results that are similar to those of Sorek (2009). Melzer and Hins (2019) analyze the phenomenon in Germany, and unlike Huber (2014), they jointly analyze the decision to commute, migrate, or work from the place of residence. Their results show that people with less education tend to commute, but the greater the distance, the greater the probability that the worker has more education. It should be noted that Melzer and Hins (2019) indicate commuting can be done daily or weekly (remaining a certain number of days outside their residence) and so there is no distinction between urban and regional commuting.

The self-selection of workers has also been addressed within literature on migration. The analysis of self-selection is based on the Roy model (1951), which analyzes the distribution of income and the optimization that individuals perform based on their heterogeneous endowment of skills when choosing between two economic activities. In this model, individuals practice positive selection in that the economic activity that requires a higher level of skill pays a higher salary. Negative self-selection will occur for those activities requiring lower qualifications, as less-skilled workers may have a better income in that activity relative to the activity that requires higher skills. 
Borjas $(1987 ; 1999)$ formalizes Roy's model to analyze self-selection in migration to the United States, assuming that the costs of migrating are constant among individuals (they do not depend on skill level), which determines the negative self-selection of migrants, which occurs when the returns to skill is greater in the host country than in the country of origin. On the other hand, Chiquiar and Hanson (2005) and Borjas (1991) extend the model assuming that the cost of migrating depends negatively on the skill level, with which a positive, negative, or intermediate self-selection can occur, depending on the difference between the returns to schooling in the country of origin and the country of destination.

It should be noted that both the analysis of self-selection in long-distance commuting (Huber 2014; Wrede 2013; Sorek 2009) and the analysis of commuter characteristics such as qualification (Eilmsteiner-Saxinger 2011; Sandow 2011; Storey 2010, among others) have primarily been carried out considering administrative areas. We therefore add to the literature on commuting self-selection by addressing an important factor in empirical analysis, the use of labor market functional areas. Using this configuration, worker flows are more representative as those commuters who make frequent trips between adjacent administrative areas that belong to the same labor market are not counted as such. Additionally, our study focuses on directly comparing education and salary distributions between commuters and residents in Chile, a Latin American country that stands out as one of the main mining countries worldwide and where LDC has close ties to the industry. We should also note that this type of analysis has predominantly been carried out for European countries.

\section{Long-distance commuting in Chile}

In order to better capture integrated labor markets, the proposed analysis is carried out using functional areas. Functional areas better capture the dynamics of labor markets, specifically in regard to the "zoning effect" (Wicht et al. 2020) which can produce inconsistent results when different zoning systems are used (Wong 2004). Klapka et al. (2016) also find that functional areas are more suitable for spatial analysis, particularly in the labor market. These results would indicate that functional areas better capture mobility patterns in the labor market because they are better at defining the economic zones where labor markets develop. In the Chilean context, Berdegué et al. (2015) use functional areas to analyze the dynamics of income, poverty, and inequality, which allows capturing the relationships between urban centers and the surrounding rural areas. In turn, Rowe et al. (2017) highlight the relevance of using functional areas of labor markets (along with other techniques) to analyze how labor market adjustments occur in the face of changes in employment, internal migration and commuting, which can guide the development of regional labor policies.

In this research, we follow the proposal of functional areas developed by Berdegué et al. (2019), which use nighttime satellite images to identify conurbations in Chile. They make use of a dissimilarity index obtained with data from the bidirectional flow of commuters to create conurbation clusters. The result is 135 functional 

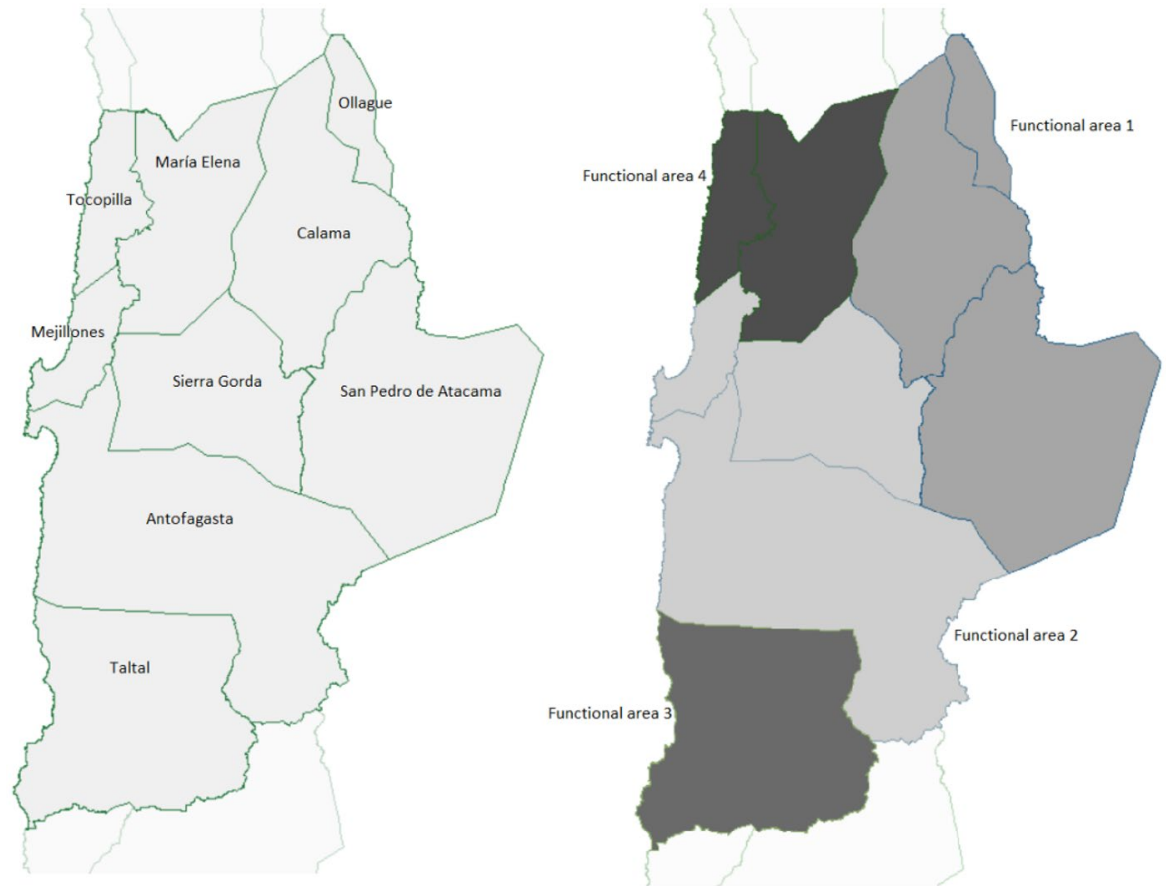

Fig. 1 Counties and functional areas in the Antofagasta region. Source: Self-elaborated according to CASEN 2009

areas rather than the 346 counties which correspond to the basic unit of the country's local administration. Figure 1 shows the functional areas for the Region of Antofagasta, in comparison with the counties, and Fig. 2 shows the distribution of commuters as a function of the distance traveled, where a significant proportion of commuters travel short distances between functional areas.

LDC in Chile is closely linked to the mining and construction sectors (construction being highly dependent on mining) (Aroca and Atienza 2008), with the two sectors responsible for approximately one in three long-distance commuters (between functional areas nationwide) in the year 2009, according to CASEN (Table 1). Other sectors where an important share of commuters' work includes social services and agriculture.

The concept of a mining settlement (a permanent residence for workers in a city built near the exploitation) and migration has been replaced by that of accommodation (a temporary or overnight stay) (Minería Chilena 2011), which allows workers to keep their original zone of residence. Labor legislation has also played a fundamental role in this dynamic by promoting labor mobility toward extraction areas through the establishment of exceptional working hours, a shift system widely used in the extractive industries and which has had a greater relevance in Chile since the 1990s. This has made it possible for workers to accumulate rest days, reducing the opportunity cost of the travel time to their zones of residence over the total rest period and therefore facilitating LDC (Manky 2017). Naturally, this has resulted 


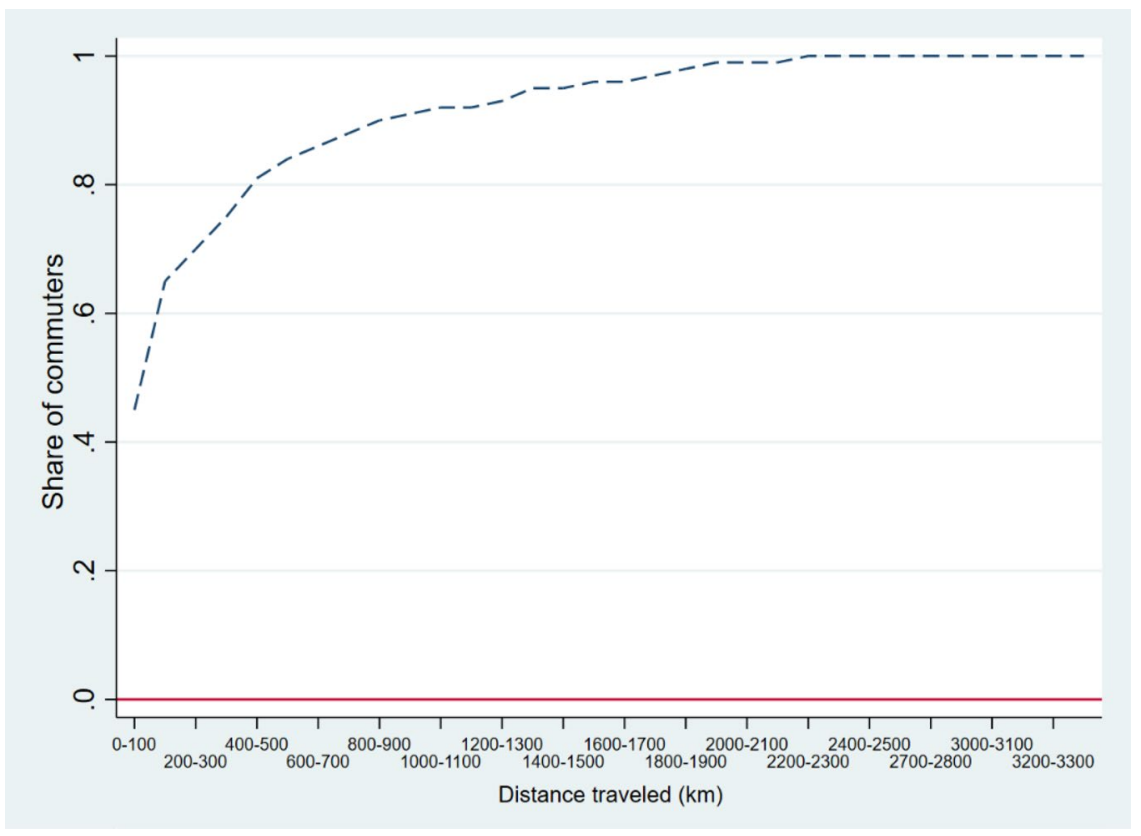

Fig. 2 Cumulative distribution of the share of commuters based on distance traveled. Source: Self-elaborated according to CASEN 2009

in the number of workers commuting between functional areas to increase, which indicates that the practice is becoming more relevant as a form of worker mobility (approximately $5.4 \%$ of those employed nationwide). However, commuting flows tend to be concentrated in specific areas. For example, about $15 \%$ of commuters in Chile travel to functional areas in the Region of Antofagasta, ${ }^{3}$ which represents on average $17 \%$ of the regional total ${ }^{4}$ between 2015 and 2019, or the Metropolitan Region of Santiago, which has the greatest weight in economic activity and employment at the national level (Fig. 3).

When analyzing the commuter flows between functional areas, we can see that functional areas in the Metropolitan Region of Santiago, Bío Bío, Valparaíso, and Antofagasta are the principal recipients of commuters. However, it should be noted that the functional areas in the Metropolitan Region receive many commuters from the neighboring regions of Valparaíso and Libertador O'Higgins, and that these areas produce daily commuting flows to and from Santiago. The commuters arriving to functional areas in Antofagasta, however, come from far away areas in the center of the country such as the Metropolitan Region and Bío Bío (Fig. 4). This is more evident when analyzing the range of distances traveled by

\footnotetext{
3 The Antofagasta Region alone is responsible for approximately $16 \%$ of the global copper production and is where the Chuquicamata mine (the largest open pit copper mine by excavated volume in the world) is located.

${ }^{4}$ Data from the Chilean National Employment Survey.
} 
Table 1 Commuters per economic sector, 2009. Source: Self-elaborated according to CASEN 2009. Commuters represent $6 \%$ of the employed population
Total Commuters

245,465

Agriculture, livestock, and fishing

$13.33 \%$

Mining and quarrying

$11.03 \%$

Manufacturing industries

$10.32 \%$

Electricity, gas, and water

$1.62 \%$

Construction

$16.68 \%$

Business

$11.18 \%$

Transportation, storage, and communications

$7.65 \%$

$5.08 \%$

Financial services

$21.79 \%$

Unspecified activities

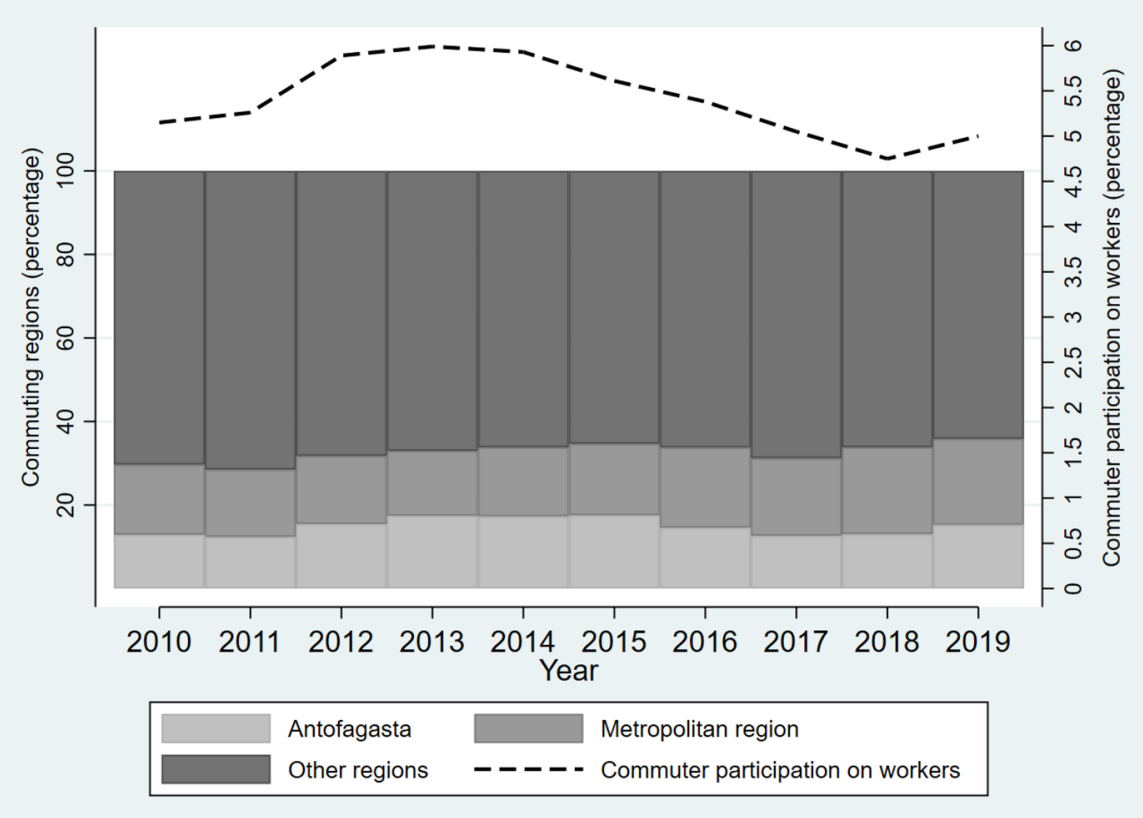

Fig. 3 Commuting flows between functional areas. Source: Self-elaborated according to the Chilean National Employment Survey (2010-2019)

the commuters in these flows. The commuter flows that reach functional areas in Antofagasta travel between 212 and $2254 \mathrm{~km}$ on average, depending on the region of origin.

Figure 5 shows that it is toward the northern and southern regions of the country that commuters travel the farthest, which can be explained by Chile's linear geography. On average, the distance traveled by these commuters (those that reach functional areas in the regions of Arica and Parinacota, Tarapacá, 


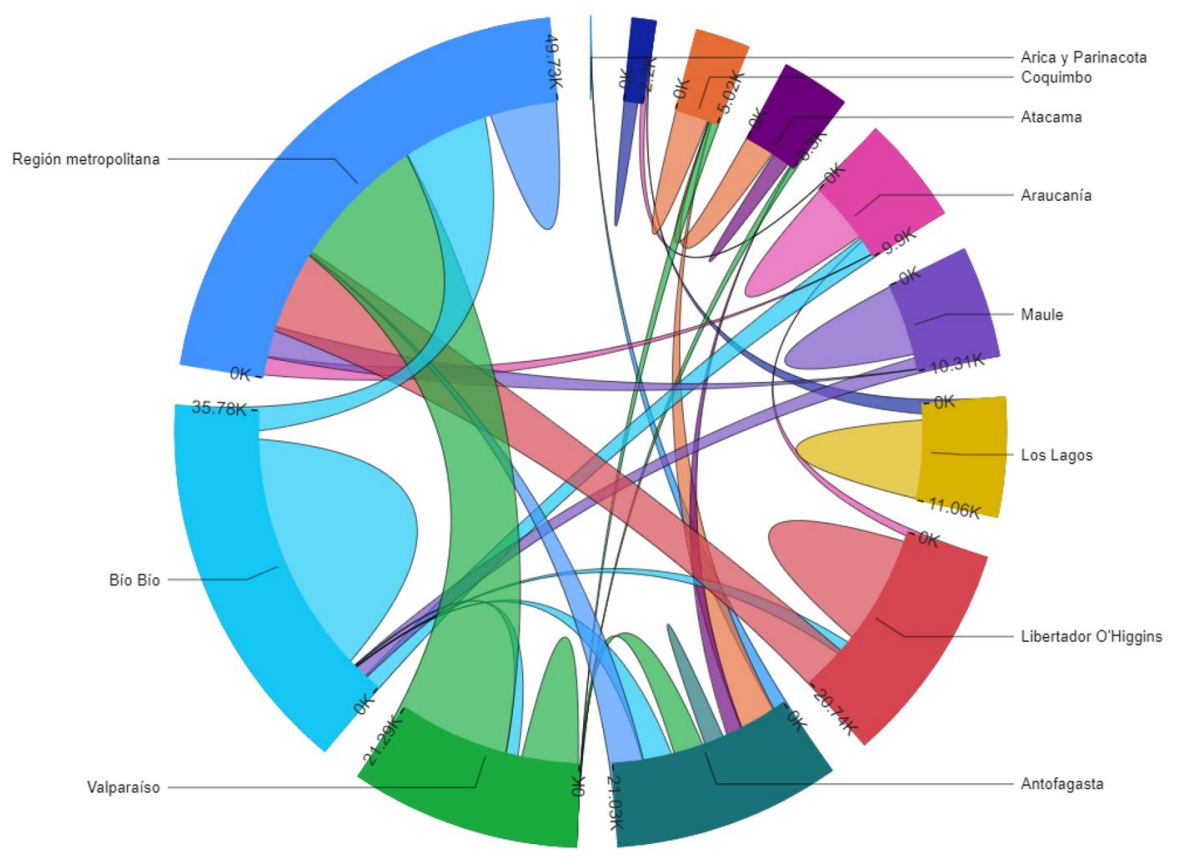

Fig. 4 Commuting flows between functional areas, by regions, 2009. Source: Self-elaborated according to CASEN 2009. Statistically representative commuting flows are shown

Antofagasta, Aysen and Magallanes and Antarctica) is greater than the distance traveled to work in other areas.

The schooling level of commuters and residents is also compared and shows that commuters have, on average, less schooling than residents (Table 2). This result is similar to that found by Huber (2014) for 14 countries in the European Union, where less qualified workers tend to commute.

Commuting in Chile is primarily long distance when the area of work is located at the extreme end of the country (mining is located in the far north). Although a significant share of commuters is employed in extractive activities, activities such as construction and other services also stand out, which leads us to consider that commuting in Chile is not exclusively a phenomenon of extractive activities. It also illustrates that the average commuter between functional areas in Chile has less education than those that work in their residence area.

\section{Theoretical framework}

The theoretical framework for identifying the existence of self-selection in commuting is supported by: (1) the job search theory and (2) the commuting and migration models. Job search theory models the decision of individuals to not participate in the labor force (those unemployed or otherwise occupied) by assuming that there are frictions in the labor market that do not allow a perfect match between supply and demand. This 


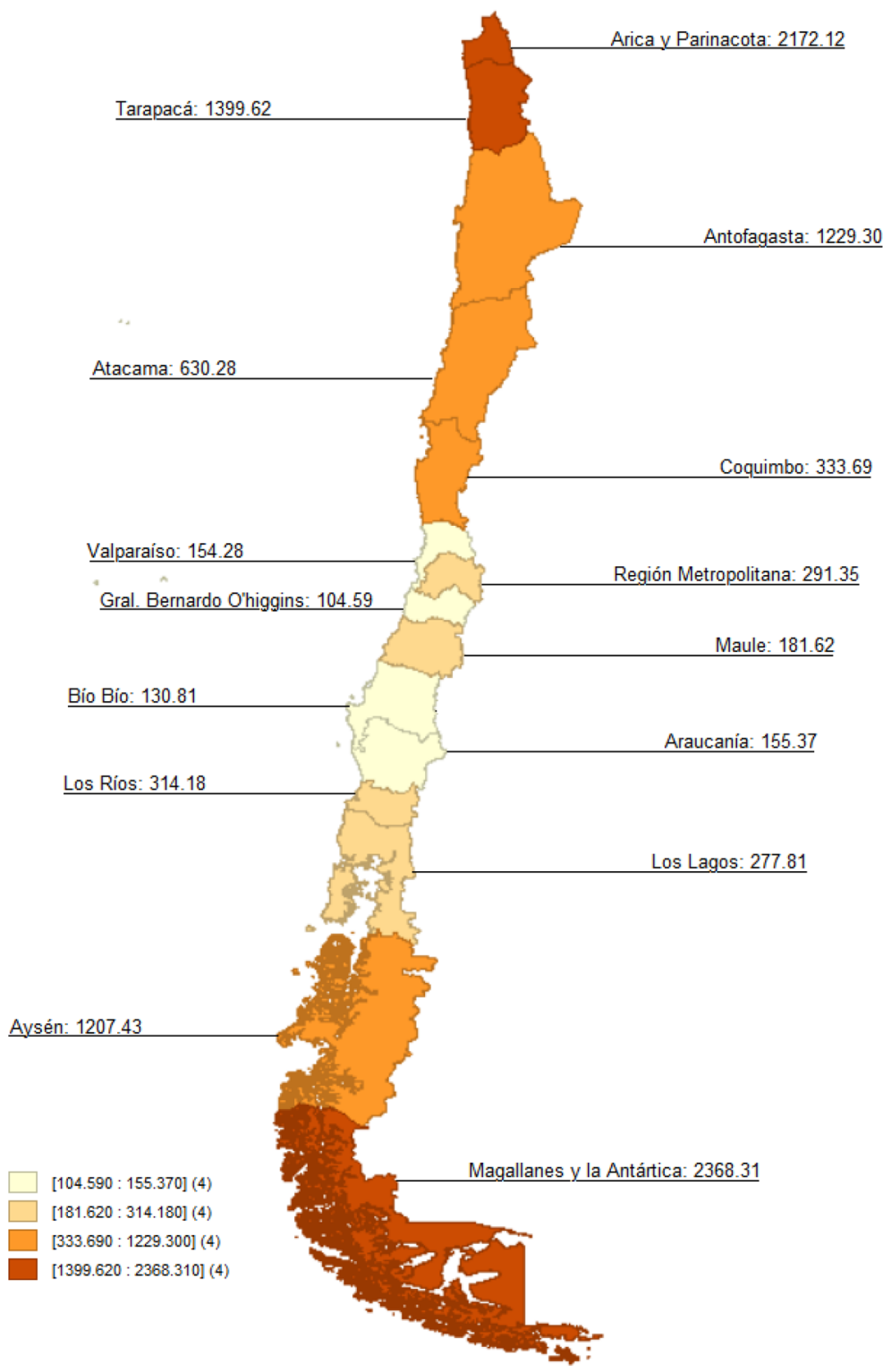

Fig. 5 Average commute distance (kilometers) between functional areas, by region, 2009. Source: Selfelaborated according to CASEN 2009. The map shows the average distance traveled by a commuter whose destination is a functional area within each region. The map is obtained from http://www.diva-gis. org. The distance is obtained from the Chilean Ministry of Public Works (http://www.vialidad.cl/produ ctosyservicios/Paginas/Distancias.aspx) 
Table 2 Schooling according to group, 2009. Source: Selfelaborated according to CASEN 2009

\begin{tabular}{lllll}
\hline & Commuter (a) & Resident (b) & (a)-(b) & $\begin{array}{l}\text { t-test } \\
\text { (a-b) }\end{array}$ \\
\hline Schooling & 11.9500 & 12.5785 & $-0.6285^{* * * *}$ & -5.26 \\
\hline
\end{tabular}

Note: $* * *$ Significant at $1 \%$; **significant at $5 \%$; ${ }^{*}$ significant at $10 \%$

results in a search cost for individuals, which can be affected by labor market conditions (van Ommeren et al. 1998). Therefore, the fact that an individual has little chance of obtaining a job in the local labor market will incentivize them to expand (geographically) their job search (Roberts and Taylor 2016).

To simplify the model, it will be assumed that the individual has already decided to participate in the workforce. The decision of interest to this study is therefore whether you choose to be employed in the job market where you live or somewhere else (to which you must commute). Because long-distance commuting implies that the place of residence is different from that of the workplace, it is assumed that if the individual decides to work somewhere else that they will not change their residence. However, changes of residence could be made to other, closer labor markets with the aim of reducing commuting costs. However, since these movements cannot be determined, they are not considered, which means that the job search framework will not be fully implemented in this analysis.

Therefore, the individual will choose to commute if their net income is greater than if they were working in their local labor market. We define the expression for net income $\left(w_{i t}\right)$ in the local labor market $(i)$ at time $t$ as follows.

$$
w_{\text {it }}=Y_{\text {it }}\left(s_{\mathrm{kt}}\right)-I_{\text {it }}-\varphi_{\text {kit }}
$$

where $Y_{i t}$ represents income in the labor market $i$ at time $t$, which depends positively on the qualification level of the individual $k, s_{k t}$. The cost of living that the individual faces in place $i$ is represented by $I_{i t}$, while $\varphi_{k i t}$ represents the cost of the job search that the individual faces in that market. Given that the individual resides and works in the same market, we assume that she does not have significant longdistance commuting costs, since her trip from the place of residence to the place of work is within the same area. Therefore, these are not represented in Eq. (1). The net income $\left(w_{j t}\right)$ in labor market $j$ is determined by the following expression.

$$
w_{\mathrm{jt}}=Y_{\mathrm{jt}}\left(s_{\mathrm{kt}}\right)-C_{\mathrm{ijt}}-I_{\mathrm{it}}-\varphi_{\mathrm{kjt}}
$$

where $Y_{j t}$ represents income in the labor market $j, C_{i j t}$ is the cost of commuting from the place of residence $(i)$ to the place of work $(j)$ and $\varphi_{k j t}$ is the cost of the job search in region $j$. The decision to commute will be made if the expected net income of region $j$ is greater than the expected net income of region $i$, considering the costs of commuting and the increase in the cost of the job search, since we assume that $\varphi_{k j t}>\varphi_{k i t}$ due to these costs depending on distance. Note that in both expressions that the cost of living is the same since the individual does not change their place of residence. Thus, the decision to commute $\left(L_{k t}\right)$ is defined by: 


$$
L_{\mathrm{kt}}=Y_{\mathrm{jt}}\left(s_{\mathrm{kt}}\right)-C_{\mathrm{ijt}}-\left(\Delta \varphi_{\mathrm{kijt}}\right)-Y_{\mathrm{it}}\left(s_{\mathrm{kt}}\right)>0
$$

where $\Delta \varphi_{\text {kijt }}$ is the variation in the search cost because it is carried out in a place other than one's residence. At this point we consider the migration models developed by Borjas (1991) and Chiquiar and Hanson (2005) for analyzing selection, both of which are based on the Roy (1951) model, where it is argued that individuals will choose the economic activity that brings them the highest expected income, based on a heterogeneous endowment of skills, and where the activities that require greater skill have a positive selection and lower skill activities will have negative selection, which has been extended to decisions to migrate and commute.

An important assumption in these models is that highly qualified (foreign) migrants face lower migration costs because they can complete any bureaucratic requirement more easily (in that they are migrating legally). As mentioned at the beginning of this section, commuting costs would also be lower for higher-qualified individuals (Ong and Blumenberg 1998; Öhman and Lindgren 2003), so $C_{i j t}$ will be defined by using schooling (as a proxy for skill) and the commute distance.

$$
C_{\mathrm{ijt}}=\theta d_{\mathrm{ijt}}-\delta s_{\mathrm{kt}}
$$

where $d_{i j t}$ is the distance between the place of residence and the place of work, and it is assumed that commuting costs increase with distance and decrease with schooling. The job search cost also depends positively on distance and negatively on qualification. A more qualified individual has better access to information that allows her to find better job openings in less time, reducing this cost (Lippman \& McCall, 1979). Additionally, searching in different labor markets increases the distance that must be traveled, which increases the search cost.

$$
\Delta \varphi_{\mathrm{kijt}}=\alpha+\mu d_{\mathrm{ijt}}-\gamma s_{\mathrm{kt}}
$$

In Eq. (5), $d_{i j t}$ represents the distance between region $i$ (the place of residence) and region $j$ (the place of work) and it is assumed that there is a base search constant $(\alpha)$ that is greater than zero. Considering Eqs. 3, 4 and 5, the decision to commute will depend positively on the level of education, provided that $\frac{\partial Y_{\mathrm{jt}}}{\partial \mathrm{s}_{\mathrm{kt}}}>\frac{\partial Y_{\mathrm{it}}}{\partial \mathrm{s}_{\mathrm{kt}}}$ as observed in (6):

$$
\frac{\partial \mathrm{L}_{t}}{\partial \mathrm{s}_{\mathrm{kt}}}=\frac{\partial Y_{\mathrm{jt}}}{\partial \mathrm{s}_{\mathrm{kt}}}+\delta+\gamma-\frac{\partial Y_{\mathrm{it}}}{\partial \mathrm{s}_{\mathrm{kt}}}>0
$$

The proposed theoretical model therefore indicates that as the level of schooling increases so do the possibilities to commute, as long as the return to education is greater in the destination area, which would determine a positive self-selection. This differential must offset the cost of commuting and the increase in the job search cost. On the other hand, if the return to education is greater in the area of residence, the people with the highest qualifications will stay there to work, which would imply that the flows of commuters are made up of people with low qualifications. The rationale behind this is that commuting may be the only alternative for these individuals to obtain a suitable job (Melzer and Hins, 2019). At this point, we find that 
the self-selection of commuters depends on regional differences in the returns to education.

Distance also affects the decision to commute. Longer commutes mean that both the cost of commuting and the cost of the job search will increase, which ultimately discourages it.

$$
\frac{\partial \mathrm{L}_{t}}{\partial \mathrm{d}_{\mathrm{ijt}}}=-\theta-\mu<0
$$

It is important to consider this effect in the methodology since it could condition the effect of schooling and subsequently the self-selection analysis. This is because longer commutes will mean less willingness to do so, regardless of your level of qualification.

\section{Methodology and data}

To analyze self-selection in commuting, Chiquiar and Hanson (2005) propose comparing the distribution of wages and schooling between residents and commuters. The distribution of wages is used since these are determined, among other factors, by individual characteristics such as education, experience, and ability, the last of which is not directly observable. The wage level will vary as a function of the individual characteristics and the valuation of said characteristics between different areas. It is proposed to compare the distribution of wages and schooling between residents and commuters by considering the zone of residence, defined as those in which the flows of commuters leaving are greater than the flows of commuters arriving, and commuter host zones, where the incoming commuter flows are greater than the outgoing ones.

The distribution of wages for commuters and residents may be different either because the qualifications between these groups are themselves different or because the market values their qualifications differently. To determine whether there are differences in the qualifications of commuters and residents in the commuters' zone of origin, a counterfactual distribution of commuter wages must be constructed. That is, a proxy of the wage that the commuters would receive if they had worked in their region of origin. The counterfactual distribution will be built based on observable characteristics and there may be unobservable factors that influence the distribution of wages that are not captured in this methodology.

Let $f^{i}(w \mid x)$ be the density function (d.f.) of wages in zone $i$, conditioned to the observable characteristics $x$ (education level and experience amongst others). The d.f. of the observable characteristics of the employed in said zone $i$ will be defined as $h\left(x \mid i, D_{i}=1\right)$ where $D_{i}$ is a variable that takes the value of 1 if the individual is employed and 0 otherwise. Therefore, the d.f. of wages observed for employed residents would be: 


$$
g\left(w \mid i, D_{i}=1\right)=\int f^{i}(w \mid x) h\left(x \mid i, D_{i}=1\right) d x
$$

Similarly, the d.f. of wages observed for commuters is determined by:

$$
g\left(w \mid j, D_{j}=1\right)=\int f^{j}(w \mid x) h\left(x \mid j, D_{j}=1\right) d x
$$

The difference between $f^{i}(w \mid x)$ and $f^{j}(w \mid x)$ captures the price difference of the individual characteristics between regions $i$ and $j$, while the difference between $h\left(x \mid i, D_{i}=1\right)$ and $h\left(x \mid j, D_{j}=1\right)$ captures the difference in characteristics between residents and commuters.

To construct the counterfactual of commuter wages had they been employed in their zone of residence, their characteristics must be valued at the price defined in zone $i$. Therefore, the d.f. of counterfactual wages is given by:

$$
g_{j}^{i}(w)=\int f^{i}(w \mid x) h\left(x \mid j, D_{j}=1\right) d x
$$

At this point, it will be assumed that the probability that a commuter is employed is one, which follows the assumption in the theoretical model that the individual had already decided to participate in the workforce. The counterfactual wage distribution will be obtained using the Coarsened Exact Matching (CEM) technique between residents and commuters based on their observable characteristics.

Matching techniques have been widely used in impact evaluation, when the control group and the treated group are not identical before the treatment is assigned. In these cases, the matching techniques aim to find, for each unit that is treated, a unit in the control group that is similar in the covariates, and the difference between different techniques is the definition of similarity used (Blackwell et al. 2009). Within this group of techniques, there are those that perform an exact match in the values of the covariates of both groups, and others such as Propensity Score Matching that perform an approximate match using distance measures on the propensity score (which is nothing more than the probability of belonging to the treated group given the covariates) (Rosenbaum and Rubin 1983). The downside is that exact matching is data-rich and produces few matches, whereas approximate matching by distance measurements requires the distance threshold to be defined (Blackwell et al. 2009).

The CEM technique takes each of the covariates and groups them temporarily according to significant strata, retaining the original values of those observations (controls and treated) that coincide within the strata of each variable. Thus, the CEM technique produces more matches than using exact matching. A disadvantage of the technique is that having few strata in each variable will lead to less balance between the treated and control group variables; however, the CEM has an algorithm that allows the strata to be defined in such a way as to limit the imbalance between the groups (Iacus et al. 2011). Another advantage of CEM is its computational efficiency when working with large data sets (Blackwell et al. 2009).

To determine the counterfactual wage of commuters, consider individuals who commute $C^{*}$ and individuals who do not commute $N C^{*}$; the CEM groups these individuals based on strata of similar characteristics which are determined by a set of 
Table 3 Wage per hour, comparison between commuters and residents. Source: CASEN, 2009

\begin{tabular}{lllll}
\hline Variable (means) & Commuters & Residents & $\begin{array}{l}\text { Commuter wage- } \\
\text { Residents wage }\end{array}$ & $\begin{array}{l}\text { T test (Commuter } \\
\text { wage-Residents } \\
\text { wage) }\end{array}$ \\
\hline Wage & $\$ 3897.12$ & $\$ 3459.32$ & $\$ 437.80$ & 1.15 \\
Contrafactual wage & $\$ 2352.42$ & - & & \\
Wage-Contrafactual wage & $\$ 1544.70^{* * *}$ & & & \\
T test (wage-Cwage) & 3.35 & & & \\
\hline
\end{tabular}

Note: *** Significant at $1 \%$; **significant at $5 \%$; *significant at $10 \%$

observable variables $X$ (Iacus et al 2012). This technique allows us to obtain a more accurate counterfactual of the wage that an individual would have earned if she had not commuted. The variables used in the CEM and that influence the decision to commute are set following Paredes et al. (2017). We consider potential experience and its square, measured as years of participation in the labor market (we assume that an individual works without interruptions after finishing their education). We also consider whether the individual is the head of their household, whether they reside in an urban area, their gender, the sector in which they work, the income of the household (deducted from the individual's wage), the occupation group ${ }^{5}$, and the contractual relationship (direct or subcontracted). The CEM is applied separately by functional areas and so commuters leaving functional area $j$ are paired with residents in functional area $j$ and not with residents from another area. It should be noted that by performing the CEM per functional area that pairing was only achieved in 75 of the 135 functional regions due to the scarcity of data. However, these 75 areas represent $93 \%$ of all commuters at the national level $(245,465)$.

Table 3 shows the average wage per hour for these commuters. The average wage for commuters between functional areas is higher than their contrafactual wage. In general, we observe that commuters receive a wage premium when commuting. However, it is also evident that the average salary of commuters is not significantly different from that of residents in functional areas.

To determine the commuters' type of self-selection, the relative density of the salary distributions of commuters and residents will be analyzed, for which the $\mathrm{R}$ "Reldist" package is used to estimate the relative density via a Gaussian estimator and via an Anscombe transformation in order to stabilize the variances (Handcock 2016). Relative density is derived following Handcock and Morris (2006), so $Y_{0}$ is a random variable for the reference population, $F_{0}(Y)$ is a cumulative distribution function (c.d.f), and $f_{0}(Y)$ is the density function (d.f.). $Y$ is also observed for

\footnotetext{
${ }^{5}$ Occupations were established in accordance with the International Standard Classification of Occupations (ISCO 08). These are: armed forces; members of the executive branch and legislative bodies; professionals, scientists and intellectuals; mid-level professional technicians; office employees; service workers and shop vendors; farmers and skilled agricultural and fishing workers; officers, operatives and artisans of mechanical arts and others; plant and machine operators and assemblers; and, unskilled workers.
} 
another population, which we will consider the comparison population, where the c.d.f. and the d.f. are $F(Y)$ and $f(Y)$, respectively. The relative distribution of $Y$ to $Y_{0}$ is defined by:

$$
G(r)=F\left(F_{0}^{-1}(r)\right)=F\left(Q_{0}(r)\right) \quad 0 \leq r \leq 1
$$

where $Q_{0}(r)$ denotes the quantile of $F_{0}$ and $r$ represents the proportion of values in said quantile. The relative density is obtained by deriving $G(r)$ :

$$
g(r)=\frac{f\left(Q_{0}(r)\right)}{f_{0}\left(Q_{0}(r)\right)} \quad 0 \leq r \leq 1
$$

In this way, the relative density can be interpreted as a ratio, where if it has a value greater than 1 , then the comparison distribution will have a higher frequency of observations. If it has a value less than 1, the comparison distribution will have a lower frequency of observations. If the relative density has a value of 1 , both distributions will have the same frequency of observations.

In this analysis, residents are considered to be the reference population and commuters the comparison population. Therefore, in the case of a positive self-selection of commuters, the relative density function should have a value greater than 1 in the highest quantiles. Negative self-selection would imply a value greater than 1 in the relative density function for the lowest quantiles. The same analysis will be applied for the distribution of schooling considering that it is a discrete variable (Handcock and Morris 2006).

\subsection{Schooling as a proxy for qualification}

As already mentioned, the distribution of wages is used to analyze whether LDC is guided by a criterion of self-selection in individuals. We use wages because they are determined, among other factors, by the skill level of the workers. However, there are external factors that can increase labor productivity, in turn increasing wages, without necessarily having higher worker qualification. Given that commuting is strongly associated with extractive activities, including mining, and that Chile is a country where copper mining is particularly relevant to its economy, there could be factors associated with this specific activity that are affecting wages. De Solminihac et al. (2018) show that labor productivity in the mining sector is positively associated with the price of copper. More specifically, an increase in the price of copper would result in higher wages in the sector by influencing labor productivity, without necessarily having an increase in the qualification of the workers.

Additionally, salary may be influenced by amenities. Authors such as Roback (1988) find that wage disparities between territories disappear when controlling for amenities. In the Chilean context, Paredes (2013) analyzes the role of amenities in the spatial wage differential, determining that amenities better explain the wage differential than the market access proposed in the New Economic Geography approach. Given that the salary can include other characteristics in addition to the qualification and this could mean that the salary is not so adequate to measure the 
Table 4 Descriptive statistics of salary and schooling in the sample, 2009. Source: Selfelaborated according to CASEN 2009

\begin{tabular}{lll}
\hline & Wage & Schooling \\
\hline Mean & $\$ 2134.24$ & 9.70 \\
Standard Dev & $\$ 4935.38$ & 4.01 \\
Min & $\$ 0.94$ & 0 \\
Max & $\$ 359,450.10$ & 20 \\
Obs & 50,404 & 52,514 \\
Residents & 47,094 & 49,089 \\
Commuters & 3310 & 3425 \\
\hline
\end{tabular}

qualification of individuals, especially in contexts such as Chile, the analysis is carried out on the distribution of schooling as a proxy for qualification. When analyzing schooling, it is not necessary to apply the CEM technique since this variable is observed for both commuters and residents. Therefore, the analysis of the relative density of the schooling distributions of residents and commuters is carried out directly.

\subsection{Data}

In Chile, there are two sources of information that identify an individual's place of residence and place of work and which allows us to determine the commuting flows. One of these sources is the National Employment Survey (ENE), which is carried out quarterly and collects information on the employment situation of individuals, with certain basic individual characteristics. In this survey, salary information is collected with an additional module in the last quarter of each year. The second source of information is the National Socioeconomic Characterization Survey (CASEN), which, in addition to collecting labor information, also includes socioeconomic information on the individual and their home.

In this work, we use the CASEN database because its main advantage over the ENE is that the sample size is larger, which adds more precision to our estimates. The disadvantage of the CASEN data is that the individual's workplace is only identified for 2009, and so we can only analyze commuting for that year. Following the work developed by Berdegué et al. (2019), 135 functional areas are obtained, which are used to identify the commuting flows. The sample contains a total of 52,514 observations, of which approximately $7 \%$ are commuters between functional areas (3425). Table 4 shows the descriptive statistics of the two main variables used in the analysis, observing a high variability in hourly wages. It is important to note that since salary is usually sensitive information, not all respondents report these values, therefore there are less data available for analysis. Additionally, Appendix 1 shows the variables used to implement the CEM technique and their descriptions. 

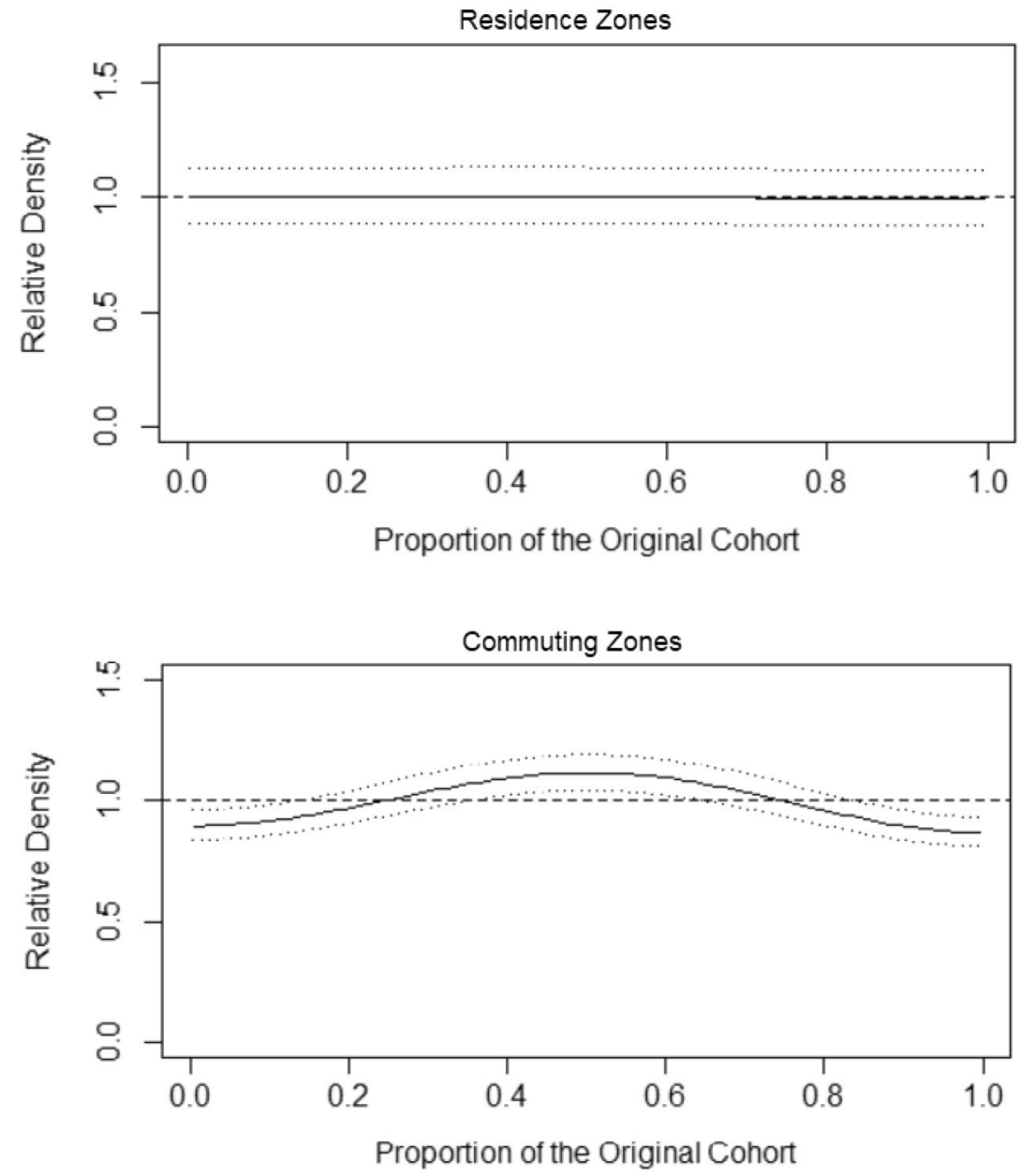

Fig. 6 Relative density of wage distribution, comparison between residence and commuting zones. Source: Self-elaborated according to CASEN 2009

\section{Results}

This section presents the results of the relative density analysis for the distributions of wages and schooling between commuters and residents. This analysis is carried out considering both zones of residence, defined as those in which the flows of commuters leaving are greater than the flows of commuters arriving, and commuter host zones, where the incoming commuter flows are greater than the outgoing flows. The results for estimating the relative densities are those obtained using the Gaussian method. The method for stabilizing the variances leads to very similar results. 

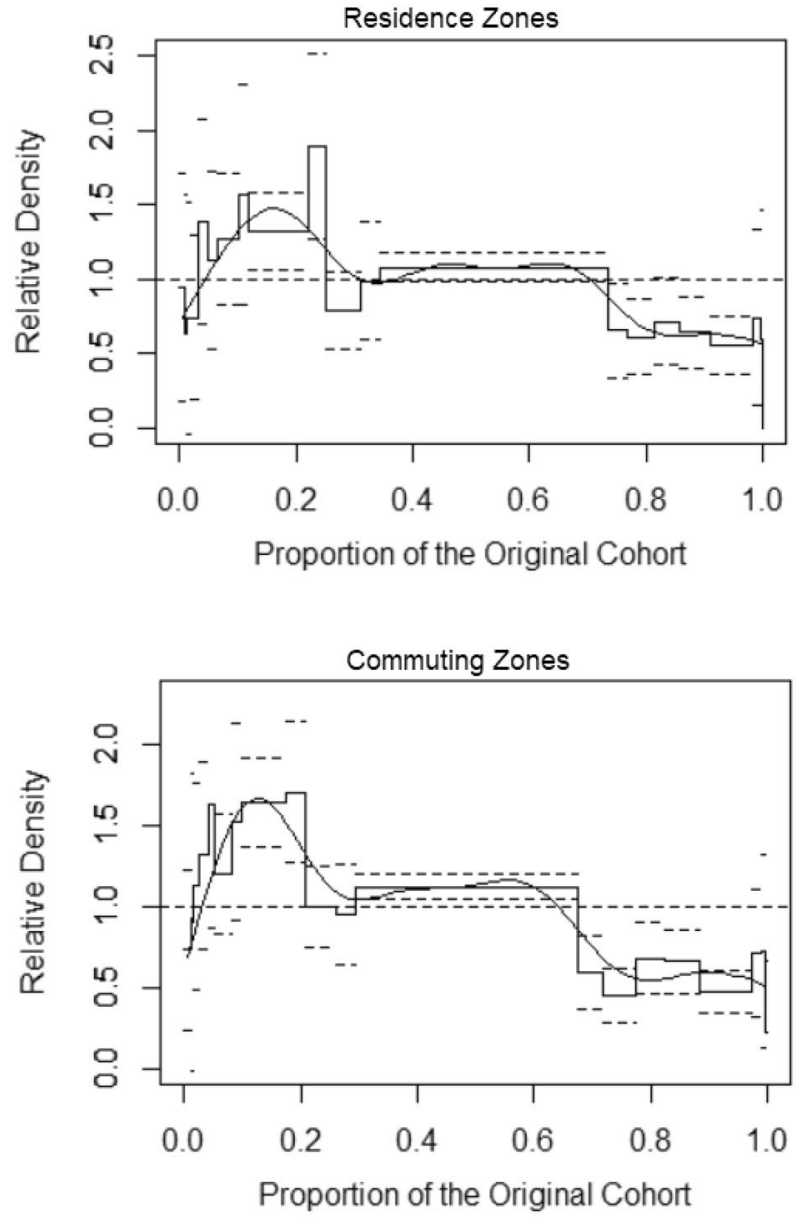

Fig. 7 Relative density of schooling distribution, comparison between residence and commuting zones. Source: Self-elaborated according to CASEN 2009

\subsection{Salary}

Using functional areas of the labor market (LMFA), the relative density of the salary distributions between commuters and residents is not statistically different from 1 for the zones of residence (upper panel in Fig. 6). Therefore, there is no evidence of self-selection in commuting in these zones. In the case of the commuting zones, a slight pattern of intermediate self-selection is evident in the lower panel. It should be noted that clearer intermediate self-selection patterns are evident when including the method to stabilize the variances. However, these results could be affected by the fact that salary captures not only the qualification and ability of the individual, but also amenities and factors that influence the copper market (for mining regions). 


\subsection{Schooling}

We observe a clear pattern of negative self-selection when analyzing functional areas by using the distribution of schooling instead of the distribution of wages. The upper panel of Fig. 7 shows that in residence zones there is a higher share of commuters with low schooling in relation to residents. However, high levels of schooling mean that the share of commuters leaving these areas is less than the share of residents (with this level of education) that do so. This pattern is accentuated in the commuting areas, which is an indication of negative self-selection in commuting. It should be noted that these patterns remain unchanged when using the variance stabilization method.

As already observed, in the context of functional areas residents have more years of schooling (on average) than commuters, resulting in an increase on the left side of the distribution and the negative selection pattern that we observe in Fig. 7. These results might indicate that the functional areas in Chile represent more competitive labor markets in terms of worker qualification, and so less qualified individuals choose to commute to nearby functional areas due to their limitations in commuting further. Commuting between said functional areas could therefore be a strategy for these individuals with lower than average qualifications.

\section{Conclusion}

The existing literature on self-selection in commuting indicates that there are several factors that influence these patterns, primarily the level of schooling and the distance traveled as well as the wage premium that commuters would receive in the work areas. Wage and schooling are also typically used as approximations for the qualification or ability of individuals. We find evidence of intermediate self-selection when analyzing the wage distributions between commuters and residents results in line with the theoretical developments of Sorek (2009) and Wrede (2013). However, when we use schooling, the result is negative self-selection in line with Huber (2014) and migration theory. The differences in our results may be due to the fact that wage picks up other factors, in which case schooling would be a better approximation of the individual's skill level. De Solminihac et al. (2018) mention this in that the price of copper is related to the productivity of the mining sector, which means higher wages without necessarily higher qualifications.

Something that the literature has not done is a self-selection analysis using functional instead of administrative areas. This document addresses this knowledge gap, and evidence of negative self-selection is found when analyzing schooling. The creation of functional areas means that the least qualified individuals have the highest probability of commuting. This could be explained by the fact that individuals with a low educational level face limitations when moving long distances (Green and Owen 2006), partly due to the higher relative cost of commuting and the low probability of finding a job that compensates them for it (Ong and Blumenberg 1998; Öhman and Lindgren 2003). 
This fact is linked to the theoretical framework since people with lower qualifications face restrictions to commuting further. Roy's model is directly applicable to commuting and shows that individuals seek to maximize their income by aligning their skills with the highest paying activity. Further, the evidence that low-skilled commuters receive a wage premium for commuting leads us to believe that it could be a strategy for improving their working conditions and their chances of finding a job, reducing the mismatch between skill and the return to skill in the labor market of residence.

This evidence is relevant in the Chilean context, where authors such as Pellandra (2015) indicate that the boom in the price of copper between 2003 and 2011 caused the wages of less-skilled workers to experience higher growth than in other groups of workers. This effect in turn had negative repercussions on school enrollment rates in mining areas, which may have had an impact on the accumulation of human capital and the employability of school dropouts at the end of the copper price boom (Pérez and Rodríguez 2021). Our results are in line with these findings and would indicate that the boom in copper prices during this period had an impact on the negative self-selection of commuters, since it was the people with fewer skills who obtained the highest salary increases, thus obtaining a higher return for their skills in the host zones of commuters that are typically specialists in the mining sector.

This result is key to understanding the current structure and dynamics of labor markets, where the situation caused by the Sars-Cov-2 pandemic in Chile has imposed different mobility restrictions between counties that belong to the same functional area within a context of restricted mobility. This "job opportunity equalizer" mechanism is restricted since it would prevent relatively less-qualified people residing in more qualified labor markets from having more job opportunities since their potential market area is reduced, having been expanded from the possibility of commuting. Education and training are key to improving not only individual employability but also the long-term competitiveness of a region (Malecki 2004). Likewise, shocks that restrict the participation of less-skilled individuals in the host labor market (like the end of the copper price boom) could lead to an increase in inequalities in local markets, as these individuals might have to settle for lower-paying jobs or face limitations to participating in their labor market. Therefore, LDC is a mechanism that improves the efficiency of the market, providing both low- and highskilled workers to labor markets where they are needed.

\section{Appendix 1: Description of variables used in the CEM}

\begin{tabular}{ll}
\hline Variables & Description \\
\hline Potential experience & $\begin{array}{c}\text { Measured as the difference between the person's age and the years of } \\
\text { schooling plus } 6\end{array}$ \\
Potential experience squared & $\begin{array}{l}\text { The potential experience squared } \\
\text { Indicates if the person is the head of the household } \\
\text { Head of household }\end{array}$ \\
Urban area & Indicates if the person lives in an urban area \\
\hline
\end{tabular}




\begin{tabular}{ll}
\hline Variables & Description \\
\hline $\begin{array}{l}\text { Gender } \\
\text { Economic sector }\end{array}$ & $\begin{array}{l}\text { Indicates the gender of the person } \\
\text { A categorical variable that reflects the economic sector in which the } \\
\text { person works (agriculture, mining, manufacturing, etc.) }\end{array}$ \\
$\begin{array}{l}\text { Household income } \\
\text { Rccupation group }\end{array}$ & $\begin{array}{l}\text { It is a categorical variable that reflects the occupation group in which the } \\
\text { person works in accordance with the International Standard Classifica- } \\
\text { tion of Occupations (ISCO 08) } \\
\text { Indicates if the person has a direct contract with the company or is sub- } \\
\text { contracted }\end{array}$ \\
\hline
\end{tabular}

Source Self-elaborated according to CASEN 2009

Acknowledgements This work has been supported by the FONDECYT Project number 1210765 "La fragmentación de la geografía del trabajo: La conmutación de larga distancia en la red de producción global de la minería en Chile" from ANID (Chile).

Funding Not applicable.

\section{Declarations}

Conflict of interest No conflict of interest has been declared by the authors.

Availability of data and material The data used in this article are available on the page of the Ministry of Social Development and Family of Chile: http://observatorio.ministeriodesarrollosocial.gob.cl/encue sta-casen-2009.

Code availability Not applicable.

Ethical approval Not applicable.

Consent to participate Not applicable.

Consent for publication Not applicable.

\section{References}

Aroca P, Atienza M (2008) La conmutación regional en Chile y su impacto en la Región de Antofagasta. EURE (santiago) 34(102):97-120

Becker K, Soosay C (2013) Labour attraction and retention in rural and remote Queensland communities. Australas J Reg Stud 19(3):342

Berdegué JA, Carriazo F, Jara B, Modrego F, Soloaga I (2015) Cities, territories, and inclusive growth: Unraveling urban-rural linkages in Chile, Colombia, and Mexico. World Dev 73:56-71

Berdegué JA, Hiller T, Ramírez JM, Satizábal S, Soloaga I, Soto J, Vargas O (2019) Delineating functional territories from outer space. Latin Am Econ Rev 28(1):4

Blackwell M, Iacus S, King G, Porro G (2009) CEM: Coarsened exact matching in Stata. Stand Genom Sci 9(4):524-546

Borjas GJ (1991) Immigration and self-selection. In Immigration trade and the labor market. University of Chicago Press, USA, pp 29-76

Borjas GJ (1987) Self-selection and the earnings of immigrants. The American economic review, $531-553$ 
Borjas GJ (1999) The Economic Analysis of Immigration. In Handbook of Labor Economics, Vol. 3A, OC Ashenfelter and D. Card, eds

Casado-Díaz J, Martínez-Bernabéu L, Rowe F (2017) An evolutionary approach to the delimitation of labour market areas: an empirical application for Chile. Spat Econ Anal 12(4):379-403

Minería Chilena (2011) 'Los nuevos asentamientos mineros.' Downloadable in: http://www.mch.cl/ reportajes/los-nuevos-asentamientos-mineros/.

Chiquiar D, Hanson GH (2005) International migration, self-selection, and the distribution of wages: evidence from Mexico and the United States. J Polit Econ 113(2):239-281

Coombes M, Casado-Díaz J (2005) The evolution of Local Labour Market Areas in contrasting region, 45th Congress of the European Regional Science Association: "Land Use and Water Management in a Sustainable Network Society", 23-27 August 2005, Amsterdam, The Netherlands, European Regional Science Association (ERSA), Louvain-la-Neuve

de Solminihac H, Gonzales LE, Cerda R (2018) Copper mining productivity: lessons from Chile. J Policy Model 40(1):182-193

Department of Sustainability, Environment, Water, Population and Communities (2011). Sustainable Australia - Sustainable Communities, Canberra: DSEWPAC.

Eilmsteiner-Saxinger G (2011) "We feed the nation": benefits and challenges of simultaneous use of resident and long-distance commuting labour in Russia's Northern Hydrocarbon Industry. J Contemp Issues Bus Gov 17(1):53

Fang H, Wang L, Yang Y (2020) Human mobility restrictions and the spread of the novel coronavirus (2019-ncov) in china (No. w26906). National Bureau of Economic Research

Gerstel N, Gross H (1984) Commuter marriage: a study of work and family. Guilford Press, USA

Gramling R, Brabant S, Forsyth C, Palmer CE (1995) Outer continental shelf issues: Central Gulf of Mexico. Final report (No. PB-96-143235/XAB). Louisiana State Univ., Baton Rouge, LA (United States). Coastal Marine Inst

Green AE, Hogarth T, Shackleton R (1999) Longer distance commuting as a substitute for migration in Britain: a review of trends, issues and implications. Int J Popul Geogr 5:49-67

Green AE, Owen D (2006) The geography of poor skills and access to work. Joseph Rowntree Foundation

Handcock MS, Morris M (2006) Relative distribution methods in the social sciences. Springer Science \& Business Media

Handcock MS (2016) Package 'reldist'

Hogarth T, Daniel WW (1988) Britain's New Industrial Gypsies: a survey long distance weekly commuting (Vol. 688). Policy Studies Institute

Houghton DS (1993) Long-distance commuting: a new approach to mining in Australia. Geogr J 159:281-290

Huber P (2014) Are commuters in the EU better educated than non-commuters but worse than migrants? Urban Stud 51(3):509-525

Iacus SM, King G, Porro G (2011) Multivariate matching methods that are monotonic imbalance bounding. J Am Stat Assoc 106:345-361

Iacus SM, King G, Porro G (2012) Causal inference without balance checking: coarsened exact matching. Polit Anal 20(1):1-24

Klapka P, Halás M, Netrdová P, Nosek V (2016) The efficiency of areal units in spatial analysis: assessing the performance of functional and administrative regions. Morav Geogr Rep 24(2):47-59

Klein B, LaRock T, McCabe S, Torres L, Privitera F, Lake B, Vespignani A (2020) Assessing changes in commuting and individual mobility in major metropolitan areas in the United States during the COVID-19 outbreak. Northeastern University. Network Science Institute. Retrieved from https://www.networkscienceinstitute.org/publications/assessingchanges-in-commuting-and-indiv idual-mobility-in-major-metropolitan-areas-in-the-united-statesduring-the-covid-19-outbreak

Lippman SA, McCall JJ (1979). Studies in the Economics of Search (Vol. 123). North Holland

Magrini S (2004) Regional (di) convergence. In Handbook of regional and urban economics (pp. 2741-2796). Elsevier

Malecki E (2004) Jockeying for position: what it means and why it matters to regional development policy when places compete. Reg Stud 38(9):1101-1120

Manky O (2017) From towns to hotels: changes in mining accommodation regimes and their effects on labour Union Strategies. Br J Ind Relat 55(2):295-320 
Markey S, Storey K, Heisler K (2011) Fly-in/Fly-out resource development: implications for community and regional development. In demography at the edge: remote human populations in developed nations (pp. 213-236)

Melzer SM, Hinz T (2019) The role of education and educational-occupational mismatches in decisions regarding commuting and interregional migration from eastern to western Germany. Demogr Res 41:461-476

Niebuhr A (2001) Convergence and the effects of spatial interaction (No. 879-2016-64393)

O'faircheallaigh C (1995) Long distance commuting in resource industries: implications for native peoples in Australia and Canada. Human Organ 54:205-213

OECD (2005) Employment outlook. OECD, Paris

Öhman M, Lindgren U (2003) Who are the long-distance commuters? Patterns and driving forces in Sweden. Cybergeo: European Journal of Geography

Ong P, Blumenberg E (1998) Job access, commute and travel burden among welfare recipients. Urban Studies 35(1):77-93

Paredes D (2013) The role of human capital, market potential and natural amenities in understanding spatial wage disparities in Chile. Spat Econ Anal 8(2):154-175

Paredes D, Soto J, Fleming DA (2017) Wage compensation for fly-in/fly-out and drive-in/drive-out commuters. Pap Reg Sci. https://doi.org/10.1111/pirs.12296

Pellandra A (2015) The commodity price boom and regional workers in Chile: a natural resources blessing? Working Paper Lacerlacea, https://pdfs.semanticscholar.org/5ecf/4f0764da5971bbc cc66bb1a8ed8731055fa6.pdf

Pérez M, Rodríguez G (2021) Economic shocks and their effect on the schooling and labor participation of youth: evidence from the metal mining price boom in Chilean counties. The Annals of Regional Science, 1-29

Pérez-Trujillo M, Oyarzo M, Paredes D (2020) Long-Distance commuting and the effect of differentiated salary expectations in the commuters' place of living on the wage obtained in the place of working. Ann Reg Sci. https://doi.org/10.1007/s00168-020-00991-7

Rapino MA, Fields AK (2013) Mega commuters in the US: time and distance in defining the long commute using the american community survey (No. Working Paper 2013-03)

Roback J (1988) Wages, rents, and amenities: differences among workers and regions. Econ Inq 26(1):23-41

Roberts J, Taylor K (2016) Intra-household commuting choices and local labour markets. Oxf Econ Pap 69(3):734-757

Rolfe J (2013) Predicting the economic and demographic impacts of long distance commuting in the resources sector: a Surat basin case study. Resour Policy 38(4):723-732

Rosenbaum PR, Rubin DB (1983) The central role of the propensity score in observational studies for causal effects. Biometrika 70(1):41-55

Rowe F, Casado-Díaz JM, Martínez-Bernabéu L (2017) Functional labour market areas for Chile. Region 4(3):R7-R9

Roy AD (1951) Some thoughts on the distribution of earnings. Oxf Econ Pap 3:135-146

Sandow E (2011) On the road: Social aspects of commuting long distances to work (Doctoral dissertation, Kulturgeografiska institutionen, Umeå universitet)

So KS, Orazem PF, Otto DM (2001) The effects of housing prices, wages, and commuting time on joint residential and job location choices. Am J Agr Econ 83(4):1036-1048

Sorek G (2009) Migration costs, commuting costs and intercity population sorting. Reg Sci Urban Econ 39(4):377-385

Storey K (2001) Fly-in/fly-out and fly-over: mining and regional development in Western Australia. Aust Geogr 32(2):133-148

Storey K (2010) Fly-in/fly-out: implications for community sustainability. Sustainability 2(5):1161-1181

Storey K, Shrimpton M (1988) "Fly-In" mining and northern development policy: the impacts of long-distance commuting in the Canadian mining sector. Impact Assess 6(2):127-136

Storey K, Shrimpton M (1986) A review of the nature and significance of the use of long distance commuting by Canadian resource industries Report prepared for Health and Welfare Canada. In: Review of Demography and the Implications for Economic and Social Policy. St. John's, NL, Canada

Van Ham M (2001) Workplace mobility and occupational achievement. Int J Popul Geogr 7:295-306 
Van Ommeren JN, van der Straaten JW (2008) The effect of search imperfections on commuting behaviour: evidence from employed and self-employed workers. Reg Sci Urban Econ 38(2):127-147

Van Ommeren JN, Rietveld P, Nijkamp P (1998) Spatial moving behavior of two-earner households. J Reg Sci 38(1):23-41

Wicht A, Kropp P, Schwengler B (2020) Are functional regions more homogeneous than administrative regions? A test using hierarchical linear models. Pap Reg Sci 99(1):135-164

Wong DW (2004) The modifiable areal unit problem (MAUP). In WorldMinds: geographical perspectives on 100 problems (pp. 571-575). Springer, Dordrecht

Wrede M (2013) Heterogeneous skills, migration, and commuting. Pap Reg Sci 92(2):345-360

Publisher's Note Springer Nature remains neutral with regard to jurisdictional claims in published maps and institutional affiliations. 